\title{
Food and Drug Interactions
}

\author{
Jong Hwan Choi ${ }^{1}$ and Chang Mann $\mathrm{Ko}^{2, *}$ \\ Departments of ${ }^{1}$ Biochemistry and ${ }^{2}$ Pharmacology, Yonsei University Wonju College of Medicine, Wonju, Korea
}

Natural foods and vegetal supplements have recently become increasingly popular for their roles in medicine and as staple foods. This has, however, led to the increased risk of interaction between prescribed drugs and the bioactive ingredients contained in these foods. These interactions range from pharmacokinetic interactions (absorption, distribution, metabolism, and excretion influencing blood levels of drugs) to pharmacodynamic interactions (drug effects). In a quantitative respect, these interactions occur mainly during metabolism. In addition to the systemic metabolism that occurs mainly in the liver, recent studies have focused on the metabolism in the gastrointestinal tract endothelium before absorption. Inhibition of metabolism causes an increase in the blood levels of drugs and could have adverse reactions. The food-drug interactions causing increased blood levels of drugs may have beneficial or detrimental therapeutic effects depending on the intensity and predictability of these interactions. It is therefore important to understand the potential interactions between foods and drugs should and the specific outcomes of such interactions.

Key Words: Food, Drug, Pharmacodynamic interaction, Pharmacokinetic interaction

\section{INTRODUCTION}

Food is one of the most important components of a healthy lifestyle. Recent studies have focused on the active role of food products on health and longevity, specifically on preventing cardiovascular and malignant diseases. In this regard, the consumption of natural foods and vegetal supplements has increased spectacularly over the last few decades raising concerns over the potential interactions between food products and drugs particularly in patients undergoing chronic therapy. Therefore, this review briefly summarizes

Received: December 29, 2016, Accepted: January 5, 2017

\section{*Corresponding author: Chang Mann Ko}

Department of Pharmacology, Yonsei University Wonju College of Medicine, 20 Ilsan-ro, Wonju, Gangwon-do 26426, Republic of Korea Tel: 82-33-741-0301, Fax: 82-33-742-4966

E-mail: changmko@yonsei.ac.kr

(c) This is an Open Access article distributed under the terms of the Creative Commons Attribution Non-Commercial License (http://creativecommons.org/ licenses/by-nc/4.0) which permits unrestricted noncommercial use, distribution, and reproduction in any medium, provided the original work is properly cited. food-drug interactions focusing on recent findings. A fooddrug interaction is the consequence of a physical, chemical, or physiologic relationship between a drug and a product consumed as food or a nutrient present in a botanically-derived food or dietary supplement [1]. The influence of dietary substances on drug effects depends on numerous variables ranging from physicochemical properties of the drug to host factors such as enzymes and transporters in the gastrointestinal (GI) tract [2] as well as in the entire body. The interactions may affect not only blood levels of drugs through pharmacokinetic change (absorption, distribution, metabolism and excretion, pharmacokinetic interactions), but also the actual effects of drugs (pharmacodynamic interactions).

\section{PHARMACODYNAMIC INTERACTION}

Some foods attenuate or enhance drug effects and toxicity by interfering with drug actions, mechanisms and the pharmacodynamics of the drug. Examples of pharmacodynamic interactions are as follows: 
The anti-coagulant warfarin antagonizes vitamin $\mathrm{K}_{1}$ recycling leading to the depletion of active vitamin $K_{1}$. However, green leafy vegetables or "greens" contain large amounts of vitamin $\mathrm{K}_{1}$ reversing its depletion. Similarly, renin-angiotensin system inhibitors increase plasma potassium $\left[\mathrm{K}^{+}\right]$levels due to a reduction in aldosterone activity. However, foods rich in $\left[\mathrm{K}^{+}\right]$such as oranges and bananas may cause hyperkalemia resulting in cardiac arrest and death due to myocardial arrhythmia. In addition, a hypertensive crisis can result from the ingestion of tyramine-rich foods (fermented foods such as wine and cheese) in conjunction with monoamine oxidase inhibitors (MAOIs). MAOIs, used to treat depression, inhibit the breakdown of endogenous and dietary amines. Consequently, MAOIs reduce the breakdown of tyramine, a precursor of catecholamines (endogenous vasoconstrictors), and raise catecholamine biosynthesis causing a hypertensive crisis [3].

All these pharmacokinetic interactions of food and drug are relatively easy to predict and are recognized and examined during the drug development stage.

\section{PHARMACOKINETIC INTERACTION}

Pharmacokinetic interactions cause an increase or decrease in the blood levels of drugs and therefore, their effects and toxicities.

\section{Pharmacokinetic interactions caused by physico- chemical properties}

The physiochemical properties of food products may cause changes in the pharmacokinetics of drugs by chemically binding to the drug and converting it into an insoluble salt that is not easily absorbed. For example, proteins in the food would bind to the antiepileptic agent, phenytoin, resulting in reduced phenytoin absorption and potentially inadequate seizure control [4]. Some tetracyclines and fluoroquinolones can bind to divalent cation-containing products (e.g., calcium in dairy) resulting in reduced drug absorption and potential therapeutic failure [5].

On the other hand, foods rich in fat can increase drug absorption by improving the solubility of lipid soluble drugs, such as some antiretroviral protease inhibitors (e.g., saquinavir and atazanavir) [6]. Food products may also affect drug absorption by delaying gastric emptying, stimulating/increasing bile or splanchnic blood flow, increasing/decreasing GI $\mathrm{pH}$, or changing the gut flora through mechanical or physiological mechanisms.

\section{Pharmacokinetic interactions related with enzymes and transporters}

Most of the pharmacokinetic interactions occur when food alters the activities of the enzymes and/or transporters involved in drug pharmacokinetic processes. To investigate these pharmacokinetic interactions, the enzymes or transporters involved in the interaction and the active compounds contained in the food working on them must be clarified. However, food products contain too many compounds making it difficult to investigate all of them. Consequently, most studies focused firstly on the phytochemicals contained in the dietary supplements consumed for health, such as natural food, vegetal extracts, and commonly consumed fruit juices, teas, and alcoholic drinks. A number of studies have investigated the effects of phytochemicals on drug metabolism. It has however been challenging to conclusively indicate the effect of phytochemicals on drug metabolism because of the discrepancies observed between in vitro and in vivo studies [7]. The results obtained in vitro have frequently failed to be replicated in vivo probably because of the following reasons: (1) insufficient concentration(s) of causative ingredients at the enzyme or transporter active site, (2) metabolism of causative ingredients to inactive products, or (3) transport of causative ingredients out of target cells (e.g., enterocytes and hepatocytes) [8].

Recent reports have shown that dietary substances elicit a significant influence on drug absorption particularly in the GI tract, the primary portal for drugs and dietary substances. In this case, dietary substances do not have to be taken up by the body and therefore do not undergo metabolism. Attention is drawn to the modulation of the metabolizing enzymes, as well as uptake and efflux transporters located particularly in the GI tract [9]. Inhibition of metabolism and active efflux in the GI tract would be expected to increase systemic drug exposure enhancing the effect and toxicity of drugs while the inhibition of active uptake would produce a completely opposite result. Many phytochemicals have been shown to inhibit these processes held 
in the GI tract in vitro. However, clinical applications remain insignificant or undetermined.

More details are discussed below regarding metabolic enzymes and transporters, and the actual influences on drug actions mediated by the enzymes and/or transporters affected by actual dietary substances.

\section{Metabolizing enzymes and presence in the Gl enterocyte}

\section{1) Cytochrome $P 450$}

Cytochrome P450s are a superfamily of enzymes (encoded by the gene CYP) involved in the phase 1 metabolism of xenobiotics and endogenous compounds [10]. The 3 families of CYP1, CYP2, and CYP3, and CYP3A4, CYP1A2, and CYP2C9 from these families constitute the major liver enzymes in the human body. The prevalence of these enzymes in human hepatic smooth endoplasmic reticulum is as follows: CYP3A4 (30\%), CYP2C9 (20\%), CYP1A2 (13\%), CYP2E1 (7\%), CYP2A6 (4\%), CYP2D6 (2\%), and CYP2B6 (1\%) [11].

CYP3A4 is also a major CYP located in the villous tips of the enterocytes lining the duodenum to the distal jejunum. These destroy drugs before they reach the systemic circulation (pre-systemic metabolism, a sort of first pass metabolism). CYP3A is responsible for the oxidative metabolism of more than half of the pharmaceutical agents on the market [12].

\section{2) Esterase}

Esterases are enzymes that metabolize inactive biological compounds, known as prodrugs, to their active form in the body through hydrolytic cleavage of the ester bond to form the active species. Inhibition of enteric esterase activity by dietary substances in rats has been shown to increase stability of the ester in the lumen and enterocytes, resulting in higher absorption of the ester and higher exposure to active metabolites via rapid hydrolysis in the plasma [13]. The clinical significance of esterase inhibition by dietary substances remains under investigation.

\section{Transporters and Presence in the Gl enterocytes}

Several types of transporters (transporting proteins) are involved in the absorption and distribution of macro- molecules including drugs in the body.

\section{1) P-glycoprotein}

$\mathrm{P}-$ glycoprotein $(\mathrm{P}-\mathrm{gp})$ is a membrane protein that protects cells by extruding toxic/unknown substances from cells. P-gp is highly expressed in tissues that have direct contact with xenobiotics such as the epithelium of the gastro-intestinal tract (the polarized apical membranes of enterocytes), the renal proximal tubule (at the brush border level), the canalicular surface of hepatocytes, and the endothelial cell surface of the blood brain barrier [14,15]. Cancer cells can often develop resistance not only to anti-cancer agents which they have been exposed to, but also to other drugs and chemicals that they have yet to come in contact with [15]. Some dietary supplements have a major influence on P-glycoprotein-mediated transport, thus interfering with anti-cancer therapies.

In the GI tract, P-gp is also expressed on the apical (luminal) membrane of enterocytes where drugs are pumped back into the intestinal lumen, lowering the systemic drug concentration [16]. It can therefore be postulated that the inhibition of enteric P-gp may increase systemic drug exposure. However, it has been difficult to establish an in vivo model to study intestinal P-gp largely because an ideal P-gp probe substrate has not been identified and several drugs transported by P-gp are also metabolized by CYP3A [17]. Therefore, it remains to be seen whether the increase in serum levels of CYP3A/P-gp substrates that occur after ingestion of dietary substances that inhibit both CYP3A and P-gp has an effect on CYP3A and P-gp individually or both.

\section{2) Organic anion transporting polypeptide}

In contrast to $\mathrm{P}-\mathrm{pg}$, organic anion transporting polypeptides (OATPs), a type of transmembrane transport protein, facilitate the uptake of a number of endogenous compounds (e.g., bile acids, hormones) and drugs [18]. Of the 11 human OATP family members, OATP1A2 and OATP2B1 have been reported to be expressed on the apical membranes of enterocytes [19]. A decrease in the drug concentration in systemic circulation could be attributed to the inhibition of an apically located intestinal uptake transporter. 


\section{PHARMACOKINETIC INTERACTIONS OF ACTUAL DIETARY SUPPLEMENTS}

\section{Grapefruit juice}

Juice prepared from grapefruit (Citrus $\times$ paradisi Macfad.) is one of the most extensively studied dietary substances shown to inhibit CYP3A. Ingredients of grapefruit juice (GFJ) such as flavonoids, naringenin, and apigenin are reported to inhibit the liver enzymes CYP3A4 and CYP1A2 [20]. Since CYP3A is located in the liver as well as in the intestine, GFJ may influence its drug metabolism process in both sites. The main difference between these two interactions would lie in the changes in the half life $\left(T_{1 / 2}\right)$ of the blood concentration of the drug. The inhibition of hepatic metabolism in the liver would increase $T_{1 / 2}$, but inhibition at the intestine would cause no change.

Co-administration of GFJ (250 mL daily for more than three months) with the anticancer drug docetaxel was reported to cause dermatologic toxicity in a patient. Two weeks after stopping GFJ administration, the area under the curve (AUC) in the blood concentration of docetaxel decreased by $60 \%$ with $\mathrm{T}_{1 / 2}$ acceleration and the adverse reaction disappeared [21]. In another case study, the administration of amiodarone, an anti-arrhythmic drug, to a patient who regularly consumed GFJ ( $\geq 1-1.5$ L/day) resulted in a marked QT prolongation associated with ventricular arrhythmia including an episode of torsade de pointes [22]. These two case reports are in line with previous findings that GFJ inhibits hepatic and intestinal cytochrome P450 enzymes, in particular CYP3A. Bailey et al. [23] also indicated that GFJ inhibits the drug pre-systemic metabolism mediated by CYP, particularly the isoform CYP3A4 in the bowel. On the other hand, Kupferschmidt et al. [24] did not observe any significant changes on the half-life of either orally or intravenously administered midazolam in a patient drinking GFJ regularly. Compelling evidence, therefore, indicates that GFJ indeed enhances systemic drug exposure by inhibiting CYP3A mediated pre-systemic (first-pass) metabolism in the intestine without changing $\mathrm{T}_{1 / 2}$ [25].

The inhibition of CYP3A4 may be induced after consuming 200-300 $\mathrm{mL}$ of GFJ, while the effect of increasing the bioavailability and toxicity of the drugs may occur in the first 24 hours after consumption. Compounds known as fur- anocoumarins (e.g., 6',7'-dihydroxybergamottin, bergamottin), in aggregate, have been established as the major mediators of the 'GFJ effect' in humans. Modes of intestinal CYP3A inhibition include reversible and mechanism-based processes as well as degradation of the protein [26]. Similar effects were noted in several fruit juices in extensive studies held in vitro and in human participants.

It has also been demonstrated in vitro that GFJ flavonoids have esterase inhibitory activity and this concept provides an explanation of their plausible mechanism of interaction with ester prodrugs [27]. However, contributions of these effects in patients are not significant in the interactions of GFJ with drugs.

GFJ also acts on drug transporter proteins (such as P-gp) at the intestinal level. Unfortunately, however, it also inhibits hepatic P-gp, without affecting the activity of liver CYP3A4 [28]. Some of the flavonoid compounds present in grapefruit (quercetin and naringenin) also inhibit transporter proteins of organic cations (OCT) and organic anion transporters (OAT) from the basal membrane of intestinal epithelium [29].

There are several reports demonstrating the inhibition of OATP at the intestinal level. GFJ significantly reduced the mean AUC of aliskiren, a direct renin inhibitor, by $61 \%$ with no observable change in half-life, consistent with the inhibition of intestinal but not hepatic OATPs in 11 healthy volunteers who were administered GFJ (200 mL single-strength three times daily for five days) and aliskiren (150 mg on day 3) [30]. Similarly, the mean AUC decreased by $38 \%$ after GFJ in healthy subjects receiving $300 \mathrm{mg}$ aliskiren and either water or GFJ (300 mL) [31]. In these cases, the average IC50 was well below the reported range of concentrations in grapefruit juice [31]. The clinical significance of the SLCO2B1*3 polymorphism has also been demonstrated in patients with asthma receiving the leukotriene receptor antagonist montelukast in adults [32] and children [33]. Unfortunately, the results regarding the influence of GFJ on the drug transporters (P-gp, OCT, and OAT) are premature, and larger trials are needed to demonstrate reproducibility of the clinical observations.

The most important drugs mentioned in the literature that interact with GFJ in terms of adverse events are calcium channel blockers (amlodipine, felodipine, manidipine, ni- 
cardipine, nifedipine, nimodipine, nisoldipine, nitrendipine, pranidipine, etc.), angiotensin II receptor blockers (losartan), beta-blockers (talinolol and acebutolol), some antiarrhythmic drugs (amiodarone, quinidine, disopyramide, and propafenone), anti-cancer agents (vinblastine), and some statins (atorvastatin) [10,34,35]. The increase in systemic drug exposure can be sufficient to produce adverse events such as muscle pain with some statins and severe hypotension with some calcium channel blockers.

Focusing on the adverse events of drugs, it is the current medical recommendation that individuals avoid grapefruit juice consumption while taking these types of drugs. Very recently, however, questions have been asked as to whether GFJ should be recommended rather than avoided [36] based on a report by Lee et al. [37]. Lee et al. [37] demonstrated that GFJ increased the blood levels of simvastatin and lovastatin by about $260 \%$ and hence enhanced their therapeutic effects by reducing LDL cholesterol levels by $37 \%$ and ischemic heart disease risk by $61 \%$. The report indicated that increments in rhabdomyolysis risk after GFJ consumption were minimal compared to the greater benefit of preventing heart disease caused by statins. The report therefore suggested that GFJ juice should probably not be contraindicated in people taking statins.

As described above, there is compelling evidence that interactions between drugs and GFJ may have potential therapeutic benefits. However, more studies are needed to overcome the challenges hindering the exploration of these beneficial therapeutic effects such as the uncertainty regarding their intensity and interaction predictability [36].

\section{Alcoholic beverages}

Growing evidence supporting the cardio-protective benefits of alcoholic beverages has promoted moderate alcohol consumption as part of a healthy lifestyle. Alcoholic drinks such as wine and beer are rich in flavonoids and other polyphenols that have antioxidant properties [38] and can alter CYP activity through mechanisms that are independent of ethanol [39]. However, data on enteric CYP3A inhibition by teas and alcoholic beverages (e.g., wine, beer) are less abundant and their clinical significance remains to be determined [40].

\section{1) Red wine}

There have been many studies investigating the interactions between red wine, made from the common grape (Vitis vinifera L.), and clinical drugs. However, the findings from the studies have been inconsistent or clinically insignificant [41]. The magnitude of the effect of red wine on the pharmacokinetics of CYP3A substrates may depend on both the amount and type of red wine consumed. Differentiating the effects of ethanol and wine components also poses a challenge. The red wine components, trans-resveratrol and gallic acid, have been shown to inhibit hepatic CYP3A in vitro in a mechanism-based and non-competitive, reversible manner, respectively. However, enteric inhibition by red wine remains to be clearly elucidated [42].

\section{2) Beer}

Beer contains many types of phenolic acids and prenyl-flavonoids, some of which are used primarily for flavoring and preserving beer [43]. An evaluation of the inhibitory effects of a wide range of ales, lagers, specialty beers, ciders, and non-alcoholic lagers on CYP systems showed that some beers induced the inhibition of CYP3A4-mediated metabolism by up to $78 \%$. However, there were wide variations in alcohol and hop acids contents. As a result, a definitive relationship between inhibition and hops constituent levels could not be established [44]. Further studies with individual compounds are warranted to support the clinical evaluation.

\section{3) Tea}

Tea is the most widely consumed beverage in the world, second only to water. The processing technique for the leaves of the tea plant (Camellia sinensis (L.) Kuntze) dictates the level of fermentation and type of tea - white, green, black, oolong, etc. [45]. Green tea undergoes minimal oxidation during processing, ensuring high polyphenol content [46]. The predominant polyphenolic compounds are catechins, which are presumed to prevent and/or treat cancer, cardiovascular disease, and obesity [47]. The majority of controlled clinical studies evaluating the effect of repeated green tea administration (given as an extract) on CYP activity have failed to demonstrate clinically significant interactions to date [48]. 
Green tea has gathered attention due to its potential effects on OATPs. Green tea contains catechins including epigallocatechin gallate (EGCG), epicatechin (EC), epigallocatechin (EGC), and epicatechin gallate (ECG) in high concentrations. In vitro studies have shown that both EGCG and ECG inhibited both OATP2B1- or OATP1A2-mediated estrone-3-sulfate uptake by $\sim 70 \%$ and $\sim 75 \%$, respectively [49]. Interestingly, their concentrations (IC50 $<100 \mu \mathrm{M}$ ) were much lower than the concentrations in typical green tea (average $\sim 450 \mu \mathrm{M}$ ). Consumption of a cup (e.g. 240-300 mL) or two of green tea would result in intestinal concentrations of ECG and EGCG within the range that inhibits OATP activity. However, no clinical studies have reported on the significance of intestinal OATP inhibition by green tea except for several case reports on rats [50] and humans [51]. Again, larger clinical studies are needed to determine the clinical significance of these observations.

\section{POLYPHENOLS: ANTIOXIDANTS BECOMING PRO-OXIDANTS}

Antioxidant activity of polyphenols or flavonoids is believed to be the central mechanism involved in the health promoting effects of natural foods and vegetal supplements [52-54]. Flavonoids are natural polyphenols, best known as pigments responsible for a diversity of colors found in vegetables (yellow, orange, red, etc.- their name being derived from the Latin word flavus meaning yellow).

There are some problematic issues that are linked to the use of vegetal supplements and vegetal components of diet, especially when associated with classical medicines. Several reports revealed the possibility of pro-oxidant effects induced by polyphenols, which were generally known for their antioxidant effects. We should be aware that flavonoids (like many other antioxidants), can act, under certain circumstances, as pro-oxidants, for example in systems containing redox-active metals (copper, iron, etc.) [55]. The pro-oxidant activity is linked to the total number of hydroxyl groups in a flavonoid molecule. As the total number increases, the hydroxyl groups increase the risk for production of radical/nonradical reactive species (hydrogen peroxide and hydroxyl radicals) in Fenton reactions [56-59]. The flavonoid pro-oxidant function could be related to their bene- ficial functions: one example being epigallocatechin gallate which reduces $\mathrm{O}_{2}$ to yield $\mathrm{H}_{2} \mathrm{O}_{2}$ to promote apoptosis and exert cytotoxic activity against bacteria [60].

Flavonoid pro-oxidant functions could have potentially toxic effects. Some individual flavonoids, for example quercetin, particularly at high-dose levels, are able to induce toxic effects, including pro-oxidant activity, which could be related to mutagenicity and mitochondrial toxicity. For example, quercetin efficiently protects against $\mathrm{H}_{2} \mathrm{O}_{2}$ - induced DNA damage in rat lung epithelial (RLE) cells, but this protection results in a reduction in GSH levels, an increase in LDH leakage, and an increase in cytosolic free calcium concentration [61]. Ultimately, quercetin acts as a toxicant. This phenomenon has been defined as "the quercetin paradox" (the conversion of quercetin into a potential toxicant while offering protection by scavenging ROS) [61,62]. It is surmised that oxidized quercetin is generated intensely in subjects with elevated oxidative stress associated with pathological conditions (diabetes mellitus, obesity, malignancies, etc.). In the event that these subjects have low levels of $\mathrm{GSH}$, quercetin used for antioxidant reactions may become toxic making them even more susceptible to damage by quercetin oxidation metabolites [52,61]. However, this kind of toxicity would require very high concentrations $(>\mathrm{sev}-$ eral hundreds of $\mathrm{mM}$ ) $[63,64]$, indicating that quercetin use is indeed rather safe [65]. The extent to which flavonoids are able to act as anti- or pro-oxidants in vivo is still poorly understood [59].

Subjects usually consuming a rich polyphenols diet are characterized by concentrations of respective compounds ranging between 2.5 and $10 \mu \mathrm{M}$. Subjects using natural supplements can reach blood levels of over $20 \mu \mathrm{M}$ polyphenols [66-68].

\section{CONCLUSION}

Interactions between drugs and food products occur in various ways and in various steps ranging from ingestion, absorption, metabolism, and excretion of both the drug and food product. Some of the effects induced by food-drug interactions, such as an increase in the blood drug level, may have potential therapeutic benefits while some interactions may result in detrimental physiological effects. It is there- 
fore important to understand and examine the potential interactions between foods and drugs and their specific effects at an individual level.

\section{REFERENCES}

1. Genser D. Food and drug interaction: consequences for the nutrition/health status. Ann Nutr Metab 2008;52 Suppl 1:29-32.

2. Custodio JM, Wu CY, Benet LZ. Predicting drug disposition, absorption/elimination/transporter interplay and the role of food on drug absorption. Adv Drug Deliv Rev 2008;60:717-33.

3. Brown C, Taniguchi G, Yip K. The monoamine oxidase inhibitor-tyramine interaction. J Clin Pharmacol 1989; 29:529-32.

4. Lourenco R. Enteral feeding: drug/nutrient interaction. Clin Nutr 2001;20:187-93.

5. Polk RE. Drug-drug interactions with ciprofloxacin and other fluoroquinolones. Am J Med 1989;87:76S-81S.

6. Le Tiec C, Barrail A, Goujard C, Taburet AM. Clinical pharmacokinetics and summary of efficacy and tolerability of atazanavir. Clin Pharmacokinet 2005;44: 1035-50

7. Won CS, Oberlies NH, Paine MF. Mechanisms underlying food-drug interactions: inhibition of intestinal metabolism and transport. Pharmacol Ther 2012;136: 186-201.

8. Fleisher D, Li C, Zhou Y, Pao L-H, Karim A. Drug, Meal and Formulation Interactions Influencing Drug Absorption After Oral Administration. Clin Pharmacokinet 1999;36:233-54.

9. Rodriguez-Fragoso L, Martinez-Arismendi JL, OrozcoBustos D, Reyes-Esparza J, Torres E, Burchiel SW. Potential risks resulting from fruit/vegetable-drug interactions: effects on drug-metabolizing enzymes and drug transporters. J Food Sci 2011;76:R112-24.

10. Jáuregui-Garrido B, Jáuregui-Lobera I. Interacciones entre fármacos antihipertensivos y alimentos. Nutr Hosp 2012;27:1866-75.

11. Zhou S, Gao Y, Jiang W, Huang M, Xu A, Paxton JW. Interactions of herbs with cytochrome P450. Drug Metab Rev 2003;35:35-98.

12. Gibbs MA, Hosea NA. Factors affecting the clinical development of cytochrome P450 3A substrates. Clin Pharmacokinet 2003;42:969-84.

13. Liederer BM, Borchardt RT. Enzymes involved in the bioconversion of ester-based prodrugs. J Pharm Sci 2006;95:1177-95.

14. Chieli E, Romiti N, Rodeiro I, Garrido G. In vitro modulation of ABCB1/P-glycoprotein expression by polyphenols from Mangifera indica. Chem Biol Interact
2010;186:287-94.

15. Kitagawa S. Inhibitory effects of polyphenols on p-glycoprotein-mediated transport. Biol Pharm Bull 2006;29: 1-6.

16. Huang SM, Zhao H, Lee JI, Reynolds K, Zhang L, Temple R, Lesko LJ. Therapeutic protein-drug interactions and implications for drug development. Clin Pharmacol Ther 2010;87:497-503.

17. Benet LZ. The drug transporter-metabolism alliance: uncovering and defining the interplay. Mol Pharm 2009;6:1631-43.

18. Hagenbuch B, Gui C. Xenobiotic transporters of the human organic anion transporting polypeptides (OATP) family. Xenobiotica 2008;38:778-801.

19. Kim RB. Organic anion-transporting polypeptide (OATP) transporter family and drug disposition. Eur $J$ Clin Invest 2003;33 Suppl 2:1-5.

20. Doostdar H, Burke MD, Mayer RT. Bioflavonoids: selective substrates and inhibitors for cytochrome P450 CYP1A and CYP1B1. Toxicology 2000;144:31-8.

21. Valenzuela B, Rebollo J, Perez T, Brugarolas A, Perez-Ruixo JJ. Effect of grapefruit juice on the pharmacokinetics of docetaxel in cancer patients: a case report. Br J Clin Pharmacol 2011;72:978-81.

22. Agosti S, Casalino L, Bertero G, Barsotti A, Brunelli C, Morelloni S. A dangerous fruit juice. Am J Emerg Med 2012;30:248 e5-8.

23. Bailey DG, Malcolm J, Arnold O, Spence JD. Grapefruit juice-drug interactions. $\mathrm{Br}$ J Clin Pharmacol 1998;46: 101-10.

24. Kupferschmidt HH, Ha HR, Ziegler WH, Meier PJ, Krahenbuhl S. Interaction between grapefruit juice and midazolam in humans. Clin Pharmacol Ther 1995;58: 20-8.

25. Hanley MJ, Cancalon P, Widmer WW, Greenblatt DJ. The effect of grapefruit juice on drug disposition. Expert Opin Drug Metab Toxicol 2011;7:267-86.

26. Paine MF, Criss AB, Watkins PB. Two major grapefruit juice components differ in time to onset of intestinal CYP3A4 inhibition. J Pharmacol Exp Ther 2005;312: 1151-60.

27. Li P, Callery PS, Gan L-S, Balani SK. Esterase inhibition by grapefruit juice flavonoids leading to a new drug interaction. Drug Metab Dispos 2007;35:1203-8.

28. Tsukasa U, Norio YF. Effect of grapefruit juice in relation to human pharmacokinetic study. Curr Clin Pharmacol 2006;1:157-61.

29. Panchagnula R, Bansal T, Varma MVS, Kaul CL. Co-treatment with grapefruit juice inhibits while chronic administration activates intestinal P-glycoprotein-mediated drug efflux. Pharmazie 2005;60:922-7.

30. Tapaninen T, Neuvonen PJ, Niemi M. Grapefruit juice greatly reduces the plasma concentrations of the 
OATP2B1 and CYP3A4 substrate aliskiren. Clin Pharmacol Ther 2010;88:339-42.

31. Rebello S, Zhao S, Hariry S, Dahlke M, Alexander N, Vapurcuyan A, Hanna I, Jarugula V. Intestinal OATP1A2 inhibition as a potential mechanism for the effect of grapefruit juice on aliskiren pharmacokinetics in healthy subjects. Eur $J$ Clin Pharmacol 2012;68: 697-708.

32. Mougey EB, Feng H, Castro M, Irvin CG, Lima JJ. Absorption of montelukast is transporter mediated: a common variant of OATP2B1 is associated with reduced plasma concentrations and poor response. Pharmacogenet Genomics 2009;19:129-38.

33. Mougey EB, Lang JE, Wen X, Lima JJ. Effect of citrus juice and SLCO2B1 genotype on the pharmacokinetics of montelukast. J Clin Pharmacol 2011;51:751-60.

34. Ofer M, Wolffram S, Koggel A, Spahn-Langguth H, Langguth P. Modulation of drug transport by selected flavonoids: Involvement of P-gp and OCT? Eur J Pharm Sci 2005;25:263-71.

35. Owira PM, Ojewole JA. The grapefruit: an old wine in a new glass? Metabolic and cardiovascular perspectives. Cardiovasc J Afr 2010;21:280-5.

36. Wang Y, Klass E. Grapefruit with Your Statin? Am $J$ Med 2016;129:e159.

37. Lee JW, Morris JK, Wald NJ. Grapefruit juice and statins. Am J Med 2016;129:26-9.

38. Krenz M, Korthuis RJ. Moderate ethanol ingestion and cardiovascular protection: from epidemiologic associations to cellular mechanisms. J Mol Cell Cardiol 2012;52:93-104.

39. Jang GR, Harris RZ. Drug interactions involving ethanol and alcoholic beverages. Expert Opin Drug Metab Toxicol 2007;3:719-31.

40. Huang SM, Strong JM, Zhang L, Reynolds KS, Nallani S, Temple R, Abraham S, Habet SA, Baweja RK, Burckart GJ, Chung S, Colangelo P, Frucht D, Green MD, Hepp P, et al. New era in drug interaction evaluation: US Food and Drug Administration update on CYP enzymes, transporters, and the guidance process. $J$ Clin Pharmacol 2008;48:662-70.

41. Bailey D. Bergamottin, lime juice, and red wine as inhibitors of cytochrome P450 3a4 activity: comparison with grapefruit juice. Clin Pharmacol Ther 2003;73: 529-37.

42. Stupans L, Tan HW, Kirlich A, Tuck K, Hayball P, Murray M. Inhibition of CYP3A-mediated oxidation in human hepatic microsomes by the dietary derived complex phenol, gallic acid. J Pharm Pharmacol 2002;54: 269-75.

43. Huvaere K, Andersen ML, Olsen K, Skibsted LH, Heyerick A, De Keukeleire D. Radicaloid-type oxidative decomposition of beer bittering agents revealed.
Chemistry (Easton) 2003;9:4693-9.

44. Foster BC, Arnason JT, Saleem A, Tam TW, Liu R, Mao J, Desjardins S. Comparative study of hops-containing products on human cytochrome P450-mediated metabolism. J Agric Food Chem 2011;59:5159-63.

45. Sang S, Lambert JD, Ho CT, Yang CS. The chemistry and biotransformation of tea constituents. Pharmacol Res 2011;64:87-99.

46. Colalto C. Herbal interactions on absorption of drugs: Mechanisms of action and clinical risk assessment. Pharmacol Res 2010;62:207-27.

47. Antonello M, Montemurro D, Bolognesi M, Di Pascoli M, Piva A, Grego F, Sticchi D, Giuliani L, Garbisa S, Rossi GP. Prevention of hypertension, cardiovascular damage and endothelial dysfunction with green tea extracts. Am J Hypertens 2007;20:1321-8.

48. Chow HH, Hakim IA, Vining DR, Crowell JA, Cordova CA, Chew WM, Xu MJ, Hsu CH, Ranger-Moore J, Alberts DS. Effects of repeated green tea catechin administration on human cytochrome P450 activity. Cancer Epidemiol Biomarkers Prev 2006;15:2473-6.

49. Roth M, Timmermann BN, Hagenbuch B. Interactions of green tea catechins with organic anion-transporting polypeptides. Drug Metab Dispos 2011;39:920-6.

50. Qiao J, Gu C, Shang W, Du J, Yin W, Zhu M, Wang W, Han M, Lu W. Effect of green tea on pharmacokinetics of 5-fluorouracil in rats and pharmacodynamics in human cell lines in vitro. Food Chem Toxicol 2011;49: 1410-5.

51. Vischini G, Niscola P, Stefoni A, Farneti F. Increased plasma levels of tacrolimus after ingestion of green tea. Am J Kidney Dis 2011;58:329.

52. Boots AW, Haenen GR, Bast A. Health effects of quercetin: from antioxidant to nutraceutical. Eur J Pharmacol 2008;585:325-37.

53. Spanou CI, Veskoukis AS, Stagos D, Liadaki K, Aligiannis N, Angelis A, Skaltsounis A-L, Anastasiadi M, Haroutounian SA, Kouretas D. Effects of Greek legume plant extracts on xanthine oxidase, catalase and superoxide dismutase activities. J Physiol Biochem 2012;68:37-45.

54. Stagos D, Portesis N, Spanou C, Mossialos D, Aligiannis N, Chaita E, Panagoulis C, Reri E, Skaltsounis L, Tsatsakis AM, Kouretas D. Correlation of total polyphenolic content with antioxidant and antibacterial activity of 24 extracts from Greek domestic Lamiaceae species. Food Chem Toxicol 2012;50:4115-24.

55. Margina D, Ilie M, Gradinaru D, Androutsopoulos VP, Kouretas D, Tsatsakis AM. Natural products-friends or foes? Toxicol Lett 2015;236:154-67.

56. Cao G, Sofic E, Prior RL. Antioxidant and prooxidant behavior of flavonoids: structure-activity relationships. Free Radic Biol Med 1997;22:749-60. 
57. Hanasaki Y, Ogawa S, Fukui S. The correlation between active oxygens scavenging and antioxidative effects of flavonoids. Free Radic Biol Med 1994;16:845-50.

58. Heim KE, Tagliaferro AR, Bobilya DJ. Flavonoid antioxidants: chemistry, metabolism and structure-activity relationships. J Nutr Biochem 2002;13:572-84.

59. Procházková D, Boušová I, Wilhelmová N. Antioxidant and prooxidant properties of flavonoids. Fitoterapia 2011;82:513-23.

60. Nakagawa H, Hasumi K, Woo JT, Nagai K, Wachi M. Generation of hydrogen peroxide primarily contributes to the induction of $\mathrm{Fe}$ (II)-dependent apoptosis in Jurkat cells by (-)-epigallocatechin gallate. Carcinogenesis 2004;25:1567-74.

61. Boots AW, Li H, Schins RP, Duffin R, Heemskerk JW, Bast A, Haenen GR. The quercetin paradox. Toxicol Appl Pharmacol 2007;222:89-96.

62. Jacobs H, Moalin M, Bast A, van der Vijgh WJ, Haenen GR. An essential difference between the flavonoids monoHER and quercetin in their interplay with the endogenous antioxidant network. PLoS One 2010;5: e13880.

63. Wilms LC, Kleinjans JCS, Moonen EJC, Briedé JJ. Discriminative protection against hydroxyl and superoxide anion radicals by quercetin in human leucocytes in vitro. Toxicol In Vitro 2008;22:301-7.
64. Yen GC, Duh PD, Tsai HL, Huang SL. Pro-oxidative Properties of Flavonoids in Human Lymphocytes. Biosci Biotechnol Biochem 2003;67:1215-22.

65. Harwood M, Danielewska-Nikiel B, Borzelleca JF, Flamm GW, Williams GM, Lines TC. A critical review of the data related to the safety of quercetin and lack of evidence of in vivo toxicity, including lack of genotoxic/carcinogenic properties. Food Chem Toxicol 2007; 45:2179-205.

66. Margina D, Gradinaru D, Manda G, Neagoe I, Ilie M. Membranar effects exerted in vitro by polyphenols quercetin, epigallocatechin gallate and curcumin - on HUVEC and Jurkat cells, relevant for diabetes mellitus. Food Chem Toxicol 2013;61:86-93.

67. Tribolo S, Lodi F, Connor C, Suri S, Wilson VG, Taylor MA, Needs PW, Kroon PA, Hughes DA. Comparative effects of quercetin and its predominant human metabolites on adhesion molecule expression in activated human vascular endothelial cells. Atherosclerosis 2008; 197:50-6.

68. Winterbone MS, Tribolo S, Needs PW, Kroon PA, Hughes DA. Physiologically relevant metabolites of quercetin have no effect on adhesion molecule or chemokine expression in human vascular smooth muscle cells. Atherosclerosis 2009;202:431-8. 